\title{
Capital-Estado na crise contemporânea: o gerencialismo na saúde pública
}

\author{
State capital in the contemporary crisis: managerialism in public health
}

\section{Leonardo CARNUT ${ }^{*}$ Áquilas MENDES**}

\begin{abstract}
Resumo: Este artigo tem como objetivo analisar a relação entre Estado e capital na crise contemporânea, a partir das contribuições de Marx, abordando o gerencialismo na gestão pública em saúde como mecanismo essencial neste contexto. $\mathrm{O}$ artigo está estruturado em duas partes. A primeira parte analisa a forma política específica do capitalismo, na qual o Estado se constitui como sustentáculo das relações de produção. A segunda parte discute como o Estado, em face à crise do capitalismo contemporâneo, utiliza-se do gerencialismo adotando instrumentos de gestão no interior da administração pública direta, baseados na lógica do desempenho. Concluiu-se que Marx ajuda a compreender os pontos que o estágio de exploração do trabalho alcança nos dias atuais, com as formas de controle da produção do trabalho em resposta à financeirização.
\end{abstract}

Palavras-chave: Capitalismo Contemporâneo. Crise. Estado. Saúde Pública. Gerencialismo.

\begin{abstract}
This article analyses the relationship between State and capital in the contemporary crisis, based on the contributions of Marx, addressing managerialism in public health management as an essential mechanism in this context. The article has two parts. The first part analyses the specific political form of capitalism in which the State is the mainstay in the relations of production. The second part discusses how the State, in the face of the contemporary crisis of capitalism, has employed managerialism, adopting performance related management tools within direct public administration. It concludes that Marx helps us to understand the point that labour exploitation has reached today, along with the forms of the control of the production of labour developed in response to financialization.
\end{abstract}

Keywords: Contemporary Capitalism. Crisis. State. Public Health. Managerialism.

Submetido em: 15/4/2018. Aceito em: 5/7/2018.

\section{INTRODUÇÃO}

os últimos 40 anos, as economias capitalistas vêm experimentando uma crise de sobreacumulação e superprodução. Esta tem como fundamento a lei tendencial da queda da taxa de lucro, o que torna a abordagem de Marx incontornável ${ }^{1}$.

\footnotetext{
* Sociólogo. Pós-Doutor em Saúde Pública (Ciências Sociais e Humanas em Saúde) pela Faculdade de Saúde Pública da Universidade de São Paulo (FSP-USP). Professor da Universidade Federal de São Paulo (UNIFESP, São Paulo, Brasil), Centro de Desenvolvimento do Ensino Superior em Saúde (CEDESS). Rua Pedro de Toledo, n 859, São Paulo (SP), CEP.: 04039-032. E-mail: <leonardo.carnut@gmail.com>. ORC ID: $<$ http://orcid.org/oooo-0o01-6415-6977>.

${ }^{* *}$ Economista. Livre-Docente de Economia Política da Saúde, Professor da Faculdade de Saúde Pública da Universidade de São Paulo (FSP-USP, São Paulo, Brasil), Av. Dr. Arnaldo, 715, CEP: 01246-904, São Paulo, SP e Professor do Programa de Pós-Graduação em Economia Política da Pontifícia Universidade Católica (PUC-SP, São Paulo, Brasil). Rua Monte Alegre, ${ }^{\circ}$ 984, São Paulo (SP), CEP: 05014-901. E-mail: <aquilasmendes@gmail.com>. ORC ID: <http://orcid.org/oooo-0oo2-5632-4333>.
}

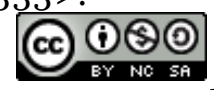

${ }^{1}$ Marx, ao se referir à crise capitalista, orienta que a dinâmica do capitalismo sempre se desenvolve acumulando contradições, que periodicamentelevam a crises (MARX, 2013). Na realidade, ao longo dos três

Argum., Vitória, v. 10, n. 2, p. 108-121, maio/ago. 2018. 
Conforme Marx, a acumulação prolongada de capital, com introdução de progresso técnico, remete ao aumento relativo de parte do capital investido em meios de produção - isto é, capital constante - e à diminuição da parte do capital investida em força de trabalho - capital variável -, elevando a composição orgânica do capital (MARX, 2017). Como os lucros são provenientes do valor adicionado pela força de trabalho, mantendo assim a taxa de exploração constante, a taxa de lucro tende a sofrer queda. No momento em que essa queda ocorre, constata-se uma crise de superacumulação, que é explicada, não pela insuficiência da demanda efetiva, mas pela ausência de lucros.

Por sua vez, para o enfrentamento dessa tendência declinante da taxa de lucro, o capital vem buscando o caminho da valorização financeira. Neste, o capital portador de juros - especialmente em sua forma mais perversa, o capital fictício - exerce sua hegemonia na dinâmica do capitalismo nesse período, principalmente depois de 1980 (CHESNAIS, 2016).

Roberts (2018) informa que a lucratividade média do capital produtivo na economia norteamericana, como um todo, manteve-se reduzida até 2016, sendo que, entre 1946 e 2016, declinou de $42 \%$ para $21 \%$.

Já o crescimento da órbita financeira pode ser entendido como resposta do capital, e de alguns estados, quando procuram oportunidades de investimento para além da economia produtiva e não lucrativa. Para se ter uma ideia, entre 1980 e 2014, os ativos financeiros globais aumentaram significativamente, passando de quase U\$ 12 trilhões para U\$ 294 trilhões, respectivamente. Nesse mesmo período, esta extraordinária expansão superou de forma considerável o crescimento do PIB mundial: em 1980, o estoque de ativos financeiros globais como percentagem do PIB representava 120\%; em 1990, 263\%; e em 2014, 378\%².

A característica permanente dos tempos contemporâneos do capitalismo é que, uma vez que a taxa de lucro está caindo e ocorre o agigantamento da esfera financeira, o capital e o Estado não permanecem passivos.

Certos setores das esquerdas mundial e brasileira advogam pelo caminho institucional das reformas por iludirem-se com a ideia de que o Estado existente possa estar a serviço de todos (CORREIA, 2015). No entanto, sendo fiel à abordagem de Marx, o Estado é el emento sui generis desta reprodução. Ou seja, o presente artigo percebe como um passo promissor nesse debate a constatação dos limites do Estado e sua intrincada relação com o modo de produção capitalista, na diacronia estabelecida nos dias atuais.

Mascaro (2013), ao se apoiar em Marx, argumenta que o político e o jurídico se estabelecem na totalidade das relações de produção, sendo entrelaçados de forma dialética, ainda que conte com a liderança das últimas, no tocante ao processo de constituição da sociabilidade. A forma política deve ser reconhecida na sua manifestação e expressão interior, porém somente consegue ser identificada, de forma estrutural, por meio da sua posição na totalidade

volumes de $O$ Capital, essa ideia-chave é sistematicamente reiterada, à medida que ele vai expondo a contradição do movimento do modo de produção capitalista, iniciando com sua argumentação desde o primeiro capítulo sobre $A$ Mercadoria, no Livro 1, e estendendo-a até o final do Livro 3.

2 Os dados têm como fonte os relatórios da McKinsey Global Institute. Disponível em: $<$ http://uk.businessinsi der.com/global-financial-assets-2015-2>.

Argum., Vitória, v. 10, n. 2, p. 108-121, maio/ago. 2018. 
das relações sociais capitalistas. Trata-se de conceber o Estado na sua associação estrutural com essas relações.

É nessa perspectiva que se pode compreender a natureza da crise do capitalismo contemporâneo, que intensifica os ataques e questiona duramente o Estado Social ${ }^{3}$, orientando-o de forma mais direta aos interesses mercantis e a processos de privatização das políticas públicas $^{4}$.

Nesse caso, o Estado brasileiro não parou de conceder apoio ao setor privado, utilizando-se de mecanismos de funcionamento que impõem riscos à saúde universal. Podem-se identificar vários aspectos que vêm marcando a atuação do Estado brasileiro, destacando-se a adoção de novas modalidades de gestão com mecanismos gerenciais mercantis - o gerencialismo -, protagonizados pelos instrumentos de desempenho (CARNUT; NARVAI, 2016).

Nessa perspectiva, este artigo tem como objetivo geral analisar a relação entre Estado e capital na crise contemporânea, a partir das contribuições de Marx, abordando o gerencialismo na gestão pública em saúde como mecanismo essencial nesse contexto.

O artigo está estruturado em duas partes. A primeira parte analisa a forma política específica do capitalismo, na qual o Estado se constitui como sustentáculo das relações capitalistas de produção. A segunda parte discute como o Estado, em face à crise do capitalismo contemporâneo, utiliza-se do gerencialismo adotando instrumentos de gestão no interior da admini stração pública direta, baseados na lógica do desempenho.

\section{O ESTADO E SUA RELAÇÃO ORGÂNICA COM O CAPITAL}

Na compreensão mais aprofundada dessa crise do capitalismo, é fundamental ressaltar o papel do Estado contemporâneo articulado com o movimento do capital. O Estado constitui expressão de uma forma social determinada, assumindo as relações de poder e de exploração nas condições capitalistas. A compreensão disto remete à análise do capital como uma relação social de produção - uma forma social - e de como a forma política se associa a essa dinâmica do capital (HIRSCH, 2010; 2017). Trata-se de referendar que a forma política, o Estado, integra as relações de produção capitalista. A especificidade do modo de produção capitalista está centrada na separação e na simultânea associação entre Estado e sociedade, política e economia (WOOD, 2010).

Por isso, entende-se que o Estado brasileiro, à medida que é parte integrante das relações capitalistas de produção, expressa sua consonância com a dinâmica do capital através de seu orçamento, por exemplo, comprometendo-se com o aumento da emissão de títulos de dívida pública e no crescimento substantivo do pagamento do serviço desta 5 .

\footnotetext{
3 Para compreender melhor a denominação "Estado Social”, ver Boschetti (2016).

4 Para o entendimento dos ataques que os Estados Sociais vêm sofrendo, ver Whal (2011).

5 Para o conhecimento da ev olução do pagamento de juros da dívida e sua representação no orçamento total da União, ver as informações da Auditoria da Dívida Cidadã. Disponível em:

<https:// auditoriacidada.org.br/conteudo/divida-publica-e-o-centro-dos-problemas-nacionais/>.
}

Argum., Vitória, v. 10, n. 2, p. 108-121, maio/ago. 2018. 
O conflito e a crise são marcas fundamentais na reprodução do sistema capitalista, eles são constitutivos. O Estado não é indiferente à reprodução econômica deste sistema, a rigor, ele é motor essencial para tal reprodução. A dinâmica do capitalismo é que funda o Estado moderno no período da acumulação primitiva de capital, não o contrário. O Estado, por meio de sua violência, já desempenhava papel central no período inicial do modo de produção capitalista, e tem sido assim na sua história. Ao se referir ao capital como uma relação social de produção, Marx (2013) situa-o muito bem como produto historicamente específico de determinada formação social e econômica, em que o poderoso domínio político do Estado moderno assegura o processo de expropriação violenta da terra ${ }^{6}$.

Nessa perspectiva, no contexto do capitalismo, é preciso ressaltar a visão de alguns autores, que não admitem conceber o Estado como algo externo ao capital ou à sociedade civil, especialmente aos efeitos da dinâmica do capitalismo contemporâneo e sua crise, com ataques aos direitos sociais, em geral, e à saúde, em particular. Trata-se de considerar que a relação Estado/capital é orgânica. Isto significa compreender que não existe separação entre o Estado e o capital; que as relações entre eles não são somente relações de exterioridade. Neste sentido, cabe aqui uma referência à contribuição do debate alemão sobre a derivação do Estado dos anos 1970, que deduz (deriva) a forma política (Estado) das contradições da dinâmica do capital, em que o caráter desta relação atribui ao Estado sua natureza capitalista, assegurando a troca das mercadorias, na sua forma-valor e a própria exploração da força de trabalho (CALDAS, 2015; BONNET; PIVA, 2017).

Tal debate sobre a derivação identifica como o Estado não constitui mero resultado da vontade da classe dominante, mas sim de um determinado modo de produção e das relações sociais que lhe são inerentes. Assim se dá o entendimento dos sentidos das contrarreformas que o Estado capitalista vem adotando no contexto do capitalismo financeirizado, e seus efeitos na saúde.

De acordo com Mascaro (2013), “[...] o Estado se revela como um aparato necessário à reprodução capitalista, assegurando a troca das mercadorias [...]” (MASCARO, 2013, p. 18), na sua forma-valor, "[...] e a própria exploração da força de trabalho sob a forma assalariada" (MASCARO, 2013, p. 18). Contudo, é importante marcar que entre a forma-valor e a forma política estatal não há um desdobramento lógico necessário, nem de total ligação funcional. Ao se moldar a um poder separado dos próprios agentes econômicos, a forma política estatal pode até mesmo ser contrária aos interesses da valorização do valor. Deste modo, é possível perceber, então, a existência de um espaço de disputa da correlação de forças no interior do Estado (forma política), que não necessariamente reveste-se de mera função das forças/formas econômicas.

Assim, uma leitura de Marx partindo da ideia de que os níveis jurídico e político se constroem com base no nível econômico, ou seja, tomando o político-jurídico como um acessório do econômico, parece ser superficial e prejudicial ao entendimento da complexidade da dinâmica do capitalismo.

\footnotetext{
${ }^{6}$ Cabe lembrar o desenvolvimento do longo trajeto histórico, expresso por extenso processo de violência do Estado, a partir dos séculos XV e XVI, como apresenta Marx no capítulo XXIV de OCapital, Livro I, denominado "A assim chamada acumulação primitiva" (MARX, 2013).
} 
Não se deve esquecer que, na constituição da forma econômica e da forma política - e no entrelaçamento de ambas -, permeiam-se, necessariamente, a história, a luta de classes e seus movimentos. O Estado, ao ter autonomia perante as classes, não revela indiferença em relação ao todo social. Mascaro (2013) é claro neste sentido: “[...] não é o domínio do Estado por uma classe que revela sua razão estrutural de ser; é a forma que revela a natureza da reprodução social” (MASCARO, 2013, p. 45). Para reforçar este argumento, cabe dizer que há uma autonomia relativa do Estado, sendo que ela está ancorada na dependência estrutural e existencial de determinado tipo de reprodução social, a capitalista. Trata-se de insistir que ela é relativa porque espelha a própria reprodução capitalista. Mascaro sintetiza: “[...] não é pelas classes que o dominam, mas pela forma, que o Estado é capitalista” (MASCARO, 2013, p. 50).

Se o Estado não pode ser compreendido como um elemento que pode resolver a crise, contrapondo-se à lógica capitalista - como muitas teorias e visões de esquerda ainda advogam, principalmente no campo da saúde pública -, tampouco pode ser entendido como elemento que prejudica o equilíbrio perfeito dos mercados, como a visão da economia neoclássica insiste em disseminar.

As formas política (Estado) e jurídica (Direito) se estabelecem na totalidade das relações de produção, entrelaçando-as. Pachukanis, ao procurar entender a essência do Estado capitali sta, promove a sua dedução lógica, desmitificando as formas política e jurídica ${ }^{7}$. Nas palavras do autor, tem-se que:

A máquina do Estado de fato se realiza como 'vontade geral' impessoal, como 'poder do Direito' etc., na medida em que a sociedade se constitui como um mercado. No mercado, cada vendedor e cada comprador é, como vimos, um sujeito jurídico par excellence. Onde surge em cena a categoria do valor e do valor de troca, a premissa é a vontade autônoma das pessoas que atuam na troca. O valor de troca deixa de ser valor de troca, e a mercadoria deixa de ser mercadoria, se a proporção de troca é definida por uma autoridade situada fora das leis imanentes do mercado. A coerção, como ordem de um homem dirigida a outro e reforçada pela força, contradiz a premissa fundamental da relação entre possuidores de mercadorias (PACHUKANIS, 2017, p. 174, grifo nosso).

Considera-se, assim, que o estudo das formas política e jurídica, como indica Pachukanis na sociedade produtora de mercadorias, deve ser semelhante àquele feito por Marx (2013) no estudo da mercadoria. Torna-se fundamental iniciar pela compreensão das categorias mais simples das relações sociais para que se recupere o trajeto do todo, da totalidade social - do processo jurídico -, definido e organizado metodologicamente. Sabe-se que, na análise da produção, Marx identifica que a mercadoria se configura como a categoria mais simples e elementar do processo. Em semelhante análise, ao observar o processo das relações jurídicas intermediadas pelo Direito, Pachukanis reconhece o sujeito como categoria mais elementar dessa relação. Neste sentido, é por meio do sujeito que se inicia a análise da forma jurídica.

\footnotetext{
7 Evguiéni B. Pachukanis, jurista soviético, escreveu, na década de 1920, seu livro Teoria Geral do Direito e Marxismo, desenvolvendo uma ideia original no interior do pensamento marxista, no tocante ao papel do Direito e do Estado na sociedade capitalista e pós-capitalista. O autor propõe uma investigação sobre o Direito com base no método da obra de maturidade de Marx, e que se refere especialmente ao texto de $O$ Capital. Para mais informações, ver Pachukanis (2017).
}

Argum., Vitória, v. 10, n. 2, p. 108-121, maio/ago. 2018. 
Considera-se, então, diante de tal análise, metodologicamente coerente, que se torna possível realizar a dedução lógica da forma jurídica a partir da forma mercadoria.

Assim, a forma política e a forma jurídica são determinadas pela forma mercadoria e definidas pela reprodução material da sociedade capitalista. Daí, no contexto contemporâneo do capitalismo em crise, ser possível compreender que o Estado desempenha um papel essencial no comando e gerenciamento das contratendências, no sentido de contrapor-se à queda da taxa de lucro ${ }^{8}$. Torna-se evidente o caráter do Estado em salvaguardar a forma do capital, colocando-se na dianteira da intensificação da exploração da força de trabalho, na garantia de instrumentos que precarizam as condições de contratação e perda de direitos sociais. Portanto, ficam claras as limitações do Estado no sentido de que não pode ser co mpreendido como um elemento potente para resolver a crise para os trabalhadores, contrapondo-se à lógica capitalista, como a visão keynesiana advoga ${ }^{9}$, principalmente no campo de reforço das políticas públicas.

É importante insistir que, no contexto do capitalismo contemporâneo e sua crise, o movimento do capital sob a dominância do capital portador de juros e sua forma - o capital fictício - não permite ilusões quanto ao papel do Estado contemporâneo. Neste sentido, as palavras de Pachukanis são um bálsamo para esse tempo histórico, à medida que não poupam críticas ao caráter do Estado de Direito:

O Estado como fator de força, tanto na política interna, como na externa: eis aí a correção que a burguesia foi forçada a fazer em sua teoria e prática do 'Estado de Direito'. Quanto mais instável se tornou a dominação da burguesia, mais comprometedora se tornou essa correção, mais depressa o 'Estado de Direito' transformou-se numa sombra imaterial, até que finalmente o excepcional aguçamento da luta de classe obrigou a burguesia a deixar completamente de lado a máscara do 'Estado de Direito’ e revelar a essência do poder como violência organizada de uma classe sobre a outra (PACHUKANIS, 2017, p. 182).

A fragilidade do Estado de Direito é perceptível nesses tempos de vigência do neoliberalismo e da valorização fictícia no movimento do capital. Na realidade, não se identifica a retirada do Estado da economia, mas ao contrário, assiste-se ao fortalecimento da rapinagem financeira em seus orçamentos. Para isto, a adoção de políticas austeras, com redução dos direitos

\footnotetext{
8 Para Marx (2107), a solução que o próprio sistema capitalista fornece ao enfrentamento da crise refere-se à realização de poderosas seis contratendências. São elas: 1) elevação do grau de exploração do trabalho, seja pelo prolongamento da jornada de trabalho, seja pela intensificação de trabalho; 2) compressão do salário abaixo de seu valor, ou seja, redução dos salários; 3) barateamento dos elementos do capital constante, buscando matérias-primas mais baratas, máquinas mais eficientes etc.; 4) aumento da superpopulação relativa, reunindo um contingente de força de trabalho além das necessidades do capital como maneira de pre ssionar o valor da força de trabalho para baixo; 5) ampliação e abertura do comércio exterior como forma de procriar o excedente produzido e encontrar fontes de matéria-prima e recursos abundantes, barateando seus custos; e 6) aumento do capital acionário, de forma a compensar a queda na tax a de lucro com juros oferec idos pelo mercado financeiro, por empresas ou por títulos do Estado.

9 Para a visão key nesiana, pode-se dizer que, de forma geral, as crises financeiras não são apenas resultados dos comportamentos irracionais dos agentes, mas decorrentes da forma de operação dos mercados financeiros globais liberalizados, inviabilizando a decisão de investir (KEY NES apud MOLLO, 2015). Tratase de considerar que a internacionalização do sistema financeiro, ao se criar um único mercado mundial de dinheiro e crédito, impõe uma configuração econômica na qual não existem regras monetário-financeiras e cambiais constantes. Neste quadro, os instrumentos tradicionais de política macroeconômica acabam sendo frágeis para barrar os colapsos financeiros e cambiais no mundo, acarretando crises de demanda efetiva.
}

Argum., Vitória, v. 10, n. 2, p. 108-121, maio/ago. 2018. 
sociais e sua mercantilização - inclusive, da política de saúde -, no mundo e no Brasil, tem sido a ordem do dia.

Assim, torna-se difícil aceitar que o Estado possa agir de forma a produzir políticas públicas em direção aos interesses que não sejam da lógica do capital. Correia (2015) é exato quando afirma que não se pode tomar a questão do perfil das políticas públicas de forma individual. Não é possível deduzir que seus resultados satisfatórios decorram da qualidade dos seus gestores, mas compreendê-los à luz da dinâmica do movimento do capital, particularmente da posição do Estado na reprodução típica da forma-valor. Fica reforçada, então, a presença do Estado no fortalecimento da lógica de valorização do capital, que intensifica a utilização de mecanismos gerencias do setor privado no seu interior, como será discutido na próxima seção.

\section{O GERENCIALISMO NA SAÚDE PÚBLICA COMO MECANISMO DO ESTADO CAPITALISTA CONTEMPORÂNEO}

O mundo do trabalho na administração pública também entra em consonância com a fase do capitalismo contemporâneo quando se compreende o Estado como forma derivada da sociabilidade capitalista. Por esta razão, foi imposta ao serviço público a utilização de concepções e técnicas de gestão do setor privado, sob o discurso da racionalização e eficiência, que ficou conhecida como gerencialismo (WOOD JR, 1995).

Não é demasiado lembrar que o processo de centralidade da gerência sobre a propriedadeacionismo foi o mecanismo que permitiu, nos anos 1980, uma melhor gestão para a expansão dos mercados financeiros e/ou sua ressurreição em alguns países. Na imbricada relação Capital-Estado, a dívida pública gera pressões fiscais fortes sobre as rendas menores e com menor mobilidade, promovendo austeridade orçamentária e paralisia das despesas públicas. Portanto, foi a dívida pública que facilitou a implantação das políticas de privatização nos países chamados em desenvolvimento (CHESNAIS, 2005).

A pecha da exterioridade à produção, fartamente descrita pela literatura marxista especializada na decodificação da crise, leva o capital portador de juros a demandar da economia mais do que ela pode dar. Por isto, Chesnais (2005) enfatiza que tal exterioridade à produção se constitui na força motriz que desregula qualitativamente o trabalho. A ordem é que todos são obrigados a se adaptar às exigências da economia, decorrendo disto as novas formas de expropriação nos países emergentes.

Nesse preâmbulo é que se encontra a contribuição do polo do trabalho, que se originou nas iniciativas privadas e hoje é o norte do trabalho nos serviços públicos. Trata-se do chicote gerencialista, que remete seus trabalhadores à brutalida de dos tempos da acumulação primitiva. Não à toa, essa forma bruta se materializa, primeiramente, na gestão dos recursos humanos, e invade a vida dos trabalhadores, para além do trabalho, gerando modalidades muito sofisticadas de modulação das relações sociais (CHESNAIS, 2005).

Por isso, Dardot e Laval (2016) lembram que há agora uma disciplina do valor acionário, que toma a forma de técnicas contábeis e avaliativas de gestão da mão de obra, cujo princípio consiste em fazer de cada assalariado uma espécie de centro de lucro individual. Esse tipo de

Argum., Vitória, v. 10, n. 2, p. 108-121, maio/ago. 2018. 
gerência visa interiorizar as coerções da rentabilidade financeira na empresa e, mais fortemente no Brasil, a partir de 1995, nos serviços públicos. Trata-se de formas de fazer com que os assalariados interiorizem novas normas de eficiência produtiva e desempenho individual.

O capital portador de juros em busca de fluxos estáveis de rendimentos privatiza os serviços públicos. Os indivíduos que fazem uso rotineiro e contínuo destes serviços são consumidores cativos, vacas leiteiras, fontes de ganhos regulares e absolutamente seguros (CHESNAIS, 2005). Para que seja cada vez mais rentável, é fundamental que a sociometabolização do capital, realizada pelo Estado, tenha, em seus hamsters, a capacidade de girar a roda cada vez mais rápido (MÉSZÁROS, 2014).

Segundo Chesnais (2005), é a criação de um novo poder administrativo que, dominando os segredos do mercado financeiro, manipula procedimentos gerenciais sob a retórica da lógica financeira. Por isto, o Estado fica subserviente a tal lógica, porque, em sua essência, nunca deixou de afagar o capital.

Na contrarreforma do Estado brasileiro, Iasi (2017) argumenta que é importante desconstruir a ideia de que "[...] as pessoas certas com as concepções corretas seriam capazes de dotar o Estado de uma eficiência no sentido a gerir políticas públicas de forma adequada” (IASI, 2017, p. 231). Ora, é fundamental reiterar veementemente que a crise não é do Estado, e muito menos de sua forma de gestão, mas do processo acima descrito, no qual o gerencialismo nos serviços públicos constitui estágio mais avançado da espoliação.

É pertinente ressaltar que, especialmente no âmbito da discussão da saúde, o gerencialismo na gestão pública tem sido amplamente estudado por uma vertente predominantemente liberal-corporativa. Esta tenta dissimular o gerencialismo como estratégia a serviço das classes dominantes, na medida em que sua essência é o Estado mais flexível, leve e ágil para atender aos requisitos necessários ao novo regime de produção comandado pela financeirização (SILVA, 2016), e não para a melhoria da atenção à população.

As principais formas materiais do gerencialismo na gestão pública que ganharam notoriedade dentro do marco do Estado Empresarial (OSZLAK, 2013) foram os agenciamentos, as parcerias público-privadas, as contratualizações por resultados e as remunerações variáveis por desempenho. Na gestão pública brasileira, essas formas ganharam respaldo jurídico pós Contrarreforma Administrativa do Aparelho do Estado, incitada por Bresser-Pereira em 1995.

Em que pese à amplitude da discussão sobre o gerencialismo e como ele se manifesta nas formas jurídico-administrativas do Estado, para garantir uma análise mais precisa, alguns recortes são necessários. Esta seção focará a questão do desempenho, e de sua avaliação como forma material que cristaliza a lógica do capital no interior da administração pública direta, superintensificando o trabalho.

Basicamente dois mecanismos podem ser identificados na lógica do desempenho, no bojo da administração pública em saúde. Um se dá através da dinâmica do capital e seu processo de acumulação no interior do Estado (CHESNAIS, 2005; MÉSZÁROS, 2014); e o outro ocorre pelo processo de socialização contemporânea entre os indivíduos e a reflexividade do desempenho no trabalho como empresariamento de si (HAN, 2015).

Argum., Vitória, v. 10, n. 2, p. 108-121, maio/ago. 2018. 
É possível perceber que a acumulação no Estado está escamoteada sob o rótulo da new public management (sinonímia para gerencialismo), fazendo o trabalhador refém dessa roda viva (ou seja, de sua intensificação). Sobre a intensificação do trabalho por peça (produto/produção), Marx já dizia:

\begin{abstract}
Na realidade, o salário por peça não expressa diretamente nenhuma relação com o valor. Não se trata de medir o valor da peça pelo tempo de trabalho nela incorporado, mas, ao contrário, de medir o trabalho gasto pelo trabalhador pelo número de peças por ele produzido. [...] Sob este aspecto, o salário por peça se torna a fonte mais fértil de descontos salariais e de fraudes capitalistas. Ele proporciona ao capitalista uma medida plenamente determinada para a intensidade do trabalho (MARX, 2013, p. 623).
\end{abstract}

Os instrumentos de gestão são excelentes métodos de se intensificar o trabalho e deles expropriar mais-valia. Essa expropriação é o produto resultante (ou, sob o rótulo gerencialista: o resultado) da ação da intensificação. Na lógica do liberalismo (que preconiza relações $l i-$ vres entre os indivíduos), o resultado é substantivado ao título de contrato ou contratualização.

Assim, a contratualizacão de resultados na gestão pública - em especial, na saúde, área cujos resultados não podem ser comparados a um processo administrativo tradicional -, torna-se o mais novo modismo. É a chamada de boas-vindas ao trabalhador, que, muitas vezes sem saída, ou seja, sem essa tal liberdade para contratualizar, se vê rendido ao processo de intensificação.

Identificada com uma proposta de contratualização com foco no controle, a admini stração pública brasileira vem desenvolvendo uma gestão na qual o alcance dos resultados vem acompanhado de mecanismos de ganhos/perdas de incentivos. Mesmo sabendo que as maiores restrições da administração pública brasileira são a rigidez de procedimentos admini strativos e uma execução orçamentária legalmente difícil, a aposta da vertente no País repousou na modificação do estilo de trabalho do servidor (GARCES; SILVEIRA, 2002).

Foi assim que a questão do desempenho adentrou a seara da administração direta. Do ponto de vista científico, o termo desempenho detém diversos sentidos e formas de aplicação, que se diferenciam, basicamente, a partir do que está sendo avaliado ou da ênfase no processo que está sob avaliação (IRWIN, 2010). Entre as diversas significações, a definida por Siqueira (2002) parece mais profícua: “[...] desempenho é uma defasagem a ser mensurada a partir de uma expectativa criada sobre determinado comportamento” (SIQUEIRA, 2002, p. 15).

De certa feita, é consensual que o desempenho esteja relacionado a uma expectativa de cumprimento comportamental previamente estabelecido. No entanto, não há consenso sobre: o comportamento do quê? Para quem? O desempenho está relacionado à lógica de superação de expectativas, que atribuem um mérito funcional àquele (algo) que executou alguma coisa além do esperado. Não obstante, desempenho pode ser entendido como uma gradação de resultados conceitualmente relacionados à busca de um prêmio por mérito atingido e, portanto, compõe a noção de justiça distributiva não por necessidade, por esforço, ou por contribuição social do serviço, mas por mérito (CARNUT, 2015).

Argum., Vitória, v. 10, n. 2, p. 108-121, maio/ago. 2018. 
Foi assim que, no paradigma gerencialista, o desempenho ficou reduzido apenas à produt ividade e à quantidade de trabalho (BARBOSA, 1996). É importante ponderar que, mesmo sob essa crítica, todo trabalho gerencial necessita ser avaliado por meio de um sistema que possibilite, por processos de retroalimentação, rever suas estratégias e métodos de trabalho. Resta aqui a problematização de como o desempenho vem sendo usado enquanto forma material de gerência para promover no trabalhador o empresariamento de si.

Em consonância com a lógica do capitalismo contemporâneo neoliberal, Han (2015) argumenta que a sociedade do século XXI não é mais a sociedade disciplinar, mas uma sociedade do desempenho. Seus habitantes também não são mais chamados de sujeitos de obediência e sim, sujeitos de desempenho e produção. São empresários de si mesmos.

Concretizada na administração pública como uma forma de empresariar a si mesmo (incorporação do desempenho como remuneração variável), o desempenho torna-se a forma material de suprimir a defasagem do trabalhador. Nesse caso, Marx já advertia, em uma passagem quase imperceptível no capítulo 19 ('Salário por Peça', em 'O Capital' - Livro I), como a defasagem salarial permite que o controle externo da produção (a supervisão) passe a ser um controle interno (ou seja, um 'autocontrole da produção').

Esse é um mecanismo técnico-gerencial potente para garantir que o trabalhador produza mais na tentativa de suprir sua defasagem individual, assim como garantir que o capitalista aumente a produção e ainda evite gastos com pessoal para supervisão do trabalho (controle externo). Marx identificou que isso seria uma 'tendência' da produção na sociabilidade capitalista, havendo a possibilidade de desenvolver-se com o avanço das forças produtivas. Segundo suas palavras, tem-se que: “[...] como a qualidade e a intensidade do trabalho são, aqui, controladas pela própria forma-salário, esta torna supérflua grande parte da supervisão do trabalho" (MARX, 2013, p. 624, grifo nosso).

É essa chave que, na produção do trabalho sob o desempenho, gera reflexivamente mais espoliação do trabalho concreto na prática dos serviços de saúde. A contínua e incessante repetição deste ciclo promove processos de trabalho que perdem o sentido de si e se transformam em números-síntese que representam, em última instância, o desempenho daquilo que poderia ser retribuível (mas não vai ser). E, na tentativa de alcançar o humanamente inalcançável, o desempenho gerencialista se agudiza, se reinventa e, no seu exercício, é capaz de fazer-se cada vez mais perverso. Isto fica bem claro na famosa frase que ganhou as mídias sociais e atualmente habita a representação da gestão na saúde pública: Se a gente alcança $a$ meta, a gente dobra meta!.

Os anseios do desempenho, já incarnados no inconsciente por meio de frases como essa, reforçam o argumento de Alemán (2017), quando diz que a narrativa da autorrealização é absoluta e estruturalmente consonante com o neoliberalismo. Assim, é como se houvesse uma cena fantasmática que estivesse fixada no inconsciente coletivo. Quanto mais se persegue sua realização (a cultura neoliberal do trabalhar), mais se realiza a reprodução do capital nas práticas de desempenho. Esta tem sido a ordem vigente no interior da admini stração direta dos serviços de saúde. 
Dados da pesquisa empírica realizada por Carnut (2015) comprovam essa teorização. Com a análise de 217 discursos captados de atores envolvidos (trabalhadores, gestores, usuários, políticos e pesquisadores) mediante o uso de uma ferramenta de avaliação de desempenho sobre o sistema de saúde - o Índice de Desempenho do Sistema Único de Saúde (IDSUS) ${ }^{10}$-, o autor demonstra como os próprios operadores da política de saúde têm dificuldades para realizar uma crítica ao procedimento gerencialista instalado.

Grande parte dos discursos, 23,04\% (50), perdia tempo comparando indevidamente sistemas de saúde entre municípios, estados e nível federal, feito este que não era metodol ogicamente viável mediante a ferramenta de desempenho utilizada. Em segundo lugar, 13,36\% (29) dos discursos gastavam seus argumentos defendendo a avaliação positiva do seu sistema de saúde, segundo os critérios da ferramenta. Apenas em terceiro lugar, 11,52\% (25) dos discursos iniciaram alguma crítica ao método e ao uso da ferramenta propriamente dita.

O mais impressionante é que $1,84 \%$ (4) dos discursos proferidos teceram elogios ao uso da ferramenta. Os argumentos fundamentais se baseavam no uso da ferramenta como um ponto de partida para a melhoria dos sistemas de saúde; o vanguardismo e pioneirismo no uso da ferramenta para avaliar os sistemas de saúde; e ainda o discurso de autoridade baseando-se em organizações internacionais, incluindo a Organização Mundial de Saúde (OMS). Nestes discursos, percebem-se o apelo à tecnicalidade, ao discurso modernizante e à sintonia com o projeto da globalização financeira.

Como identificado por Marcelino (1988), é típico dos países latino-americanos a prática de buscar resolver um problema público extraindo-se, mecanicamente, soluções gerenciais com origem no setor privado. Neste sentido, a adoção de um índice de avaliação do desempenho no âmbito da saúde como ferramenta gerencial promove mais injustiças, à medida que são divulgados resultados na forma de números-síntese que em quase nada expressam a complexidade dos sistemas de saúde.

Para se ter uma ideia, no caso do IDSUS, deduz-se que esta ferramenta está desenhada mais para oferecer respostas ao núcleo gerencialista do Estado do que para captar uma realidade concreta. Assim, esta forma de avaliar conduz a um caminho de contratualização de resultados na gestão pública que pouco ajuda o gestor a identificar os problemas que afetam o SUS, e ainda desqualifica o debate na opinião coletiva ${ }^{1 "}$.

\section{CONSIDERAÇÕES FINAIS}

Nos tempos atuais, a relação Estado-Capital tem ficado cada vez mais evidente, principalmente como forma político-jurídica de amenizar os efeitos da queda da taxa de lucro, como essência da crise capitalista. O aparato do Estado vem recorrendo ao avanço de questões mercantis no âmbito de seu interior, demonstrando sua subserviência ao processo de reprodução.

\footnotetext{
10 O Índice de Desempenho do SUS foi instituído pela portaria do Ministério da Saúde $\mathrm{n}^{0} 720$ (07/04/2011) e refere-se a um conjunto de indicadores simples e compostos, que buscam fazer uma aferição do desempenho do Sistema Único de Saúde. Ver http://idsus.saude.gov.br/avaliativo.html.

11 Para mais detalhes, ver Carnut (2015).
}

Argum., Vitória, v. 10, n. 2, p. 108-121, maio/ago. 2018. 
Nesse sentido, Marx, em sua obra, ajuda na identificação dos pontos que o estágio de exploração do trabalho alcança nos dias atuais, com as formas de controle da produção do trabalho em resposta à financeirização. Esta relação de espoliação adentra o trabalho da admini stração pública e tem consequências nefastas para a gestão na saúde pública, assunto este que a esquerda brasileira tem dificuldades para tematizar.

Então, é essencial denunciar que a ditadura dos credores e a tirania dos mercados são as responsáveis por engendrar novos mecanismos de gerência no setor público. O gerencialismo é o seu estágio de consolidação. Afinal, como não se pode ter esta ditadura sem um estado de exceção, os argumentos aqui trazidos visaram refletir sobre como as frações rentistas buscam aprofundar seu poder administrativo, completando a reestruturação produtiva no setor público. Este é o estado em que atualmente se vive.

\section{Referências}

ALEMÁN, J. Hay mucho miedo que se ponga todo mucho peor de como está. Página 12, Buenos Aires, 2017. Disponível em: <https://www.pagina12.com.ar/32831-hay-mucho-miedo-deque-se-ponga-todo-mucho-peor-de-como-esta>. Acesso em: 28 abr. 2017.

BARBOSA, L. Meritocracia à brasileira: o que é desempenho no Brasil? Revista do Serviço Público, Brasília (DF), v. 120, n. 3, p. 58-102, 1996.

BONNET, A.; PIVA, A. Prólogo. In: BONNET, A.; PIVA, A. (Comp.). Estado y capital: el debate alemán sobre la derivación del Estado. Buenos Aires: Herramienta, 2017.

BOSCHETTI, I. Assistência social e trabalho no capitalismo. São Paulo: Cortez, 2016.

CALDAS, C. O. A teoria da derivação do Estado e do direito. São Paulo: Outras Expressões, 2015 .

CARNUT, L. Crítica a modelos de avaliação de desempenho de sistemas de saúde. 2015. Tese (Doutorado em Saúde Pública)-Programa de Pós Graduação da Faculdade de Saúde Pública, Universidade de São Paulo, São Paulo, 2015.

CARNUT, L.; NARVAI, P. C. Avaliação de desempenho de sistemas de saúde e gerencialismo na gestão pública brasileira. Saúde Soc. São Paulo, v. 25, n. 2, p. 290-305, 2016.

CHESNAIS, F. Finance capital today. London: Historical Materialism Series, 2016.

CHESNAIS, F. A finança mundializada. São Paulo: Boitempo, 2005.

CORREIA, M. O. G. Por uma crítica imanente sobre os limites das políticas públicas de direitos sociais e o Estado na produção do bem comum no modo de produção capitalista. Saúde e Soc., São Paulo, v. 24, S1, p. 55-65, 2015.

DARDOT, P.; LAVAL, C. A nova razão do mundo: ensaio sobre a sociedade neoliberal. São Paulo: Boitempo, 2016. 
GARCES, A.; SILVEIRA, J. P. Gestão pública orientada por resultados no Brasil. Revista do Serviço Público, Brasília (DF), v. 53, n. 4, p. 53-77, 2002.

HAN, B. A sociedade do cansaço. Petrópolis: Vozes, 2015.

HIRSCH, J. Elementos para uma teoria materialista del estado. In: BONNET, A; PIVA, A. (compiladores). Estado y capital: el debate alemán sobre la derivación del Estado. Buenos Aires: Herramienta, 2017.

HIRSCH, J. Teoria materialista do Estado: processos de transformação do sistema capitalista de Estado. Rio de Janeiro: Revan, 2010.

IASI, M. Política, Estado e ideologia na trama conjuntural. São Paulo: ICP, 2017.

IRWIN, R. Managing performance: an introduction. Eurohealth, London, v. 16, n. 3, p. 15-16, 2010.

MARCELINO, G. F. Governo, imagem e sociedade. Brasília (DF): Fundação Centro de Formação do Servidor Público (FUNCEP), 1988. (Coleção de Administração Pública).

MARX, K. O Capital: Critica da economia política. Livro III. São Paulo: Boitempo, 2017.

MARX, K. O Capital: contribuição à crítica da economia política, Livro I. São Paulo: Boitempo, 2013.

MASCARO, A. Estado e forma política. São Paulo: Boitempo, 2013.

MÉSZÁROS, I. A montanha que devemos conquistar. São Paulo: Boitempo, 2014.

MOLLO, M. L. R. A Supremacia da Finança e a Crise. Brazilian Keynesian Review, v. 1, n. 1, p. 55-70, 2015 .

OSZLAK, O. La gestión pública post-NGP en la América Latina: balances y desafíos pendientes. In: JORNADA INAUGURAL EN LA CONFERENCIA DE LA INPAE, 9., Santiago do Chile. Tema: "Enseñanza y Pedagogía de la Gestión de Políticas Públicas: Desafios y Actualidad para un Nuevo Servicio Público". Anais... Santiago, Chile: 2013.

PACHUKANIS, E. A teoria geral do direito e o marxismo e ensaios escolhidos (19211929). São Paulo: Sundermann, 2017.

ROBERTS, M. The underlying reasons for the Long Depression. Michael Roberts Blog, Feb. 14, 2018. Disponível em: <https://thenextrecession.wordpress.com/2018/o2/14/theunderlying-reasons-for-the-long-depression/>. Acesso em: fev. 2018.

SILVA, R. R. Concepções e funções da descentralização na gestão pública democrática e no gerencialismo. Revista O Social em Questão, Rio de Janeiro, v. 19, n. 36, p. 337-358, 2016. 
SIQUEIRA, W. Avaliação de desempenho: como romper amarras e superar modelos ultrapassados. Rio de Janeiro: Reichmann \& Affonso, 2002.

WAHL, A. The rise and fall of the welfare state. London: Pluto Press, 2011.

WOOD, E. M. Democracia contra o Capitalismo: a renovação do materialismo histórico. São Paulo: Boitempo, 2010.

WOOD JR., T. Mudança organizacional. São Paulo: Atlas, 1995.

Leonardo CARNUT Trabalhou na concepção, delineamento e redação do artigo.

Pós-Doutor em Saúde Pública (Ciências Sociais e Humanas em Saúde) pela Faculdade de Saúde Pública da Universidade de São Paulo (FSP-USP), Professor da Universidade Federal de São Paulo (UNIFESP), Centro de Desenvolvimento do Ensino Superior em Saúde (CEDESS).

Áquilas MENDES Trabalhou na concepção, delineamento e redação do artigo.

Professor Doutor Livre-Docente de Economia Política da Saúde da Faculdade de Saúde Pública da Universidade de São Paulo (FSP-USP) e do Programa de Pós-Graduação em Economia Política da Pontifícia Universidade Católica (PUC-SP).

Argum., Vitória, v. 10, n. 2, p. 108-121, maio/ago. 2018. 